Original Article

\title{
Comparative analysis of the effects combined physical procedures and alpha-lipoic acid on the electroneurographic parameters of patients with distal sensorimotor diabetic polyneuropathy
}

\author{
Vesna Grbovic ${ }^{1)}$, Aleksandra Jurisic-Skevin ${ }^{1,2)}$, Svetlana Duukic ${ }^{2)}$, Srdjan Stefanovićc), \\ JASMIN NuRKOVIC ${ }^{1,3)^{*}}$ \\ 1) Center for Physical Medicine and Rehabilitation, Clinical Center Kragujevac: 30 Zmaj Jovina Street, \\ 34000 Kragujevac, Serbia \\ 2) Faculty of Medical Sciences, University of Kragujevac, Serbia \\ 3) Department of Biomedical Sciences, State University of Novi Pazar, Serbia
}

\begin{abstract}
Purpose] Painful diabetic polyneuropathy occurs as a complication in $16 \%$ of all patients with diabetes mellitus. [Subjects and Methods] A clinical, prospective open-label randomized intervention study was conducted of 60 adult patients, with distal sensorimotor diabetic neuropathy two groups of 30 patients, with diabetes mellitus type 2 with distal sensorimotor diabetic neuropathy. Patients in group A were treated with combined physical procedures, and patients in group B were treated with alpha lipoic acid. [Results] There where a statistically significant improvements in terminal latency and the amplitude of the action potential in group A patients, while group B patients showed a statistically significant improvements in conduction velocity and terminal latency of $\mathrm{n}$. peroneus. Group A patients showed a statistically significant improvements in conduction velocity and terminal latency, while group B patients also showed a statistically significant improvements in conduction velocity and terminal latency. This was reflected in a significant improvements in electrophysiological parameters (conduction velocity, amplitude and latency) of the motor and sensory nerves (n. peroneus, n. suralis). [Conclusion] These results present further evidence justifying of the use of physical agents in the treatment of diabetic sensorimotor polyneuropathy. Key words: Diabetic polyneuropathy, Physical procedures
\end{abstract}

(This article was submitted Sep. 30, 2015, and was accepted Oct. 30, 2015)

\section{INTRODUCTION}

Painful diabetic polyneuropathy occurs as a complication in $16 \%$ of all patients with diabetes mellitus ${ }^{1)}$. The prevalence in patients suffering from diabetic polyneuropathy varies from 23 to $29 \%$. The presence of neurological symptoms and/or signs in electroneurographic (ENG) findings is necessary for confirming the diagnosis of distal sensorimotor diabetic polyneuropathy (DSMP) ${ }^{3,4)}$. Slow sensitivity and motor velocity of conduction exists in clinically evident neuropathy, especially in the feet, where the peripheral nerves are the longest. The degree of deceleration of velocity conduction is proportional to the severity of the underlying disease ${ }^{5)}$.

While drug therapy has been widely researched into and is quite well defined in the treatment of diabetic neuropathy, this is not the case with physical procedures. Physical therapy for the treatment of patients with distal sensorimotor polyneuropathy has increasingly been gaining in importance, especially as an analgesic therapy. Furthermore, in previous studies have neither researched the effects of combined physical therapy on electro-diagnostic parameters, nor made comparisons the effects

*Corresponding author. Jasmin Nurkovic (E-mail: jnurkovic@gmail.com)

(C2016 The Society of Physical Therapy Science. Published by IPEC Inc.

This is an open-access article distributed under the terms of the Creative Commons Attribution Non-Commercial No Derivatives (by-nc-nd) License $<$ http://creativecommons.org/licenses/by-nc-nd/4.0/>. 
of the alpha lipoic acid. Therapies directed at the pathogenesis process of diabetic neuropathies comprise aldose reductase inhibitors, alpha-lipoic acid, benfotiamine, protein kinase $\mathrm{C}$ inhibitors, gene therapy, gamma-linoleic acid, immunotherapy, and others ${ }^{6)}$.

Alpha-lipoic acid is an antioxidant that is endogenously produced in the body and has become studies the drug of choice for the treatment of diabetic neuropathy ${ }^{7,8}$. It is particularly important to emphasize the necessity of prompt therapy, before the occurrence of severe and irreversible changes in the nerves. Alpha-lipoic acid has a clear metabolic effect, improves microcirculation, and has an anti-inflammatory effect. All these facts act synergistically and complexly in a chain of pathophysiological processes in the development of the diabetic neuropathies ${ }^{8,9)}$.

The most commonly applied physical agents are transcutaneous electrical nerve stimulation (TENS), impulse magnetic field, stable galvanization and exercise. TENS is a method of treating the symptoms of pain by stimulating the sensitive nerve endings in the skin. It the modulations the pain at the dorsal horn of the spinal cord, and is based on the theory of control of pain inputs (the gate control theory of pain) ${ }^{10-12)}$. Galvanic current causes hyperemia of the skin and deeper tissues through which it passes and reduces pain. Hyperemia improves trophic tissue, reduces swelling and inflammation and helps to alleviate the factors that induce pain ${ }^{13)}$. Physical activity is beneficial for the metabolic processes in the body of diabetic patients and is implemented as a permanent therapeutic measure (it increases the biological effectiveness of insulin, sensitivity of insulin receptors, collateral circulation and the transport of oxygen, it lowers levels of triglycerides, cholesterol and blood pressure) ${ }^{12)}$.

Clinical studies have so far investigated the effects of certain modalities of physical therapy and alpha-lipoic acid in patients with various causes and types of neuropathies $\left.{ }^{13}, 14\right)$. However, the available literature has no data on comparative, randomized studies of the effects of physical therapy and alpha lipoic acid in patients with sensory neuropathy, especially in the subgroup of patients with diabetes mellitus. Bearing in mind the significant differences between the two therapeutic strategies in terms of clinical-management and economic aspects, there is an interest in comparative studies in this field. Thus, the main objective of our research was to investigate the effect of the application of combined physical procedures to electromyoneurographic (EMNG) parameters of peripheral sensory and motor nerves (n. peroneus and n. suralis) and compare it with the effect of treatment with alpha-lipoic acid in patients with distal sensorimotor polyneuropathy.

\section{SUBJECTS AND METHODS}

A clinical, prospective open-label randomized intervention study was conducted of 60 adult (18 years or older) who were patients at the Clinical Center, Kragujevac, Center for Physical Medicine and Rehabilitation during 2012-2013. The study was approved by the Ethics Committee of the Clinical Center, Kragujevac.

The inclusion criteria of the study were: patients with DSMP for longer than two months diagnosed with the presence of signs and symptoms (pain, paresthesia, hyperesthesia to anesthesia, muscular weakness) and EMNG findings; treatment with antidiabetic therapy which had not been changed for at least 6 months; and a signed, voluntary consent to participation in the study.

The exclusion criteria were: vitamin B12 deficiency, alcoholism, chronic renal insufficiency, thyroid dysfunction, immunodeficiency, systemic connective tissue disease, severe liver damage, cerebrovascular ischemia, cardiac decompensation, acute coronary syndrome in the previous 6 months, unregulated elevated blood pressure $(>160 / 80 \mathrm{mmHg})$, treatment with chemotherapy in the last 10 years, state after severe polytrauma, as well as use of drugs that can damage the peripheral nerves (vincristine, paclitaxel, cisplatin, streptomycin, isoniazid, ethionamide, dapsone, nitrofurantoin, metronidazole, emetine, chloroquine, amiodarone, carbamazepine, phenytoin, hydralazine, indomethacin); the existence of a contraindication to the implementation any of the planned physical agents (pregnancy, fever, malignancy, acute infectious disease, decompensation of vital organs, the presence of metal in tissue, diseases or damage to the integrity of the skin at the electrode to application); or hypersensitivity to alpha-lipoic acid of 60 adult (18 years or older), galactose intolerance, glucose-galactose malabsorption or Lapp lactose deficiency.

The study was conducted during three diagnostic and therapeutic cycles, each of which lasted 16 days and the period of time between cycles was $6 \pm 1$ week with a total study duration of six months.

The subjects were divided into two groups of 30 patients with diabetes mellitus type 2 and DSMP, based on clinical symptoms and signs, as well as the parameters of EMNG findings. Using a computer random number generator, each patient was randomly allocated to one of the two experimental groups (therapeutic arms): Group A or B.

Group A patients were treated with combined physical procedures. The method of combined physical procedures included stable galvanization (SG), pulsed electromagnetic field (PEMP), TENS, and exercise. SG (Galvan plus, Electronic Design Medical, Serbia) was applied once a day for 20 minutes, using the standard rectangular electrodes placed longitudinally along both legs. The intensity was $0.1-0.5 \mathrm{~mA} / \mathrm{cm}^{2}$, depending on the subjective feelings of patients. PEMP (Magomil-2, Electronic Design Medical, Serbia) was applied once a day for 30 minutes along both lower legs and feet, over the antenna at a frequency of $10 \mathrm{~Hz}$ and intensity of $40 \mathrm{mT}$. TENS (TENS-2, Electronic Design Medical, Serbia) was applied once a day for 30 minutes along both feet longitudinally, at a frequency of $85 \mathrm{~Hz}$ and with short-term pulses (4 ms) (appliance). Exercise performed once a day for 30 minutes, according to individually tailored protocol. Active and active-assisted exercises were used to the point of pain for strengthening the muscles of the lower extremities and to increase the range of motion of all 
joints in the lower extremities.

The second group (Group B) patients were treated with alpha lipoic acid in accordance with the conditions specified in the license for marketing of the medicine in Serbia (indications, dosage regimen, precautions, etc.) and standard clinical practice. In the period from 2 to 15 days of hospitalization, patients were treated with intravenous administration of alpha lipoic acid ( $600 \mathrm{mg}$ in $500 \mathrm{ml}$ of $0.9 \% \mathrm{NaCl}$, once a day). Upon completion of hospitalization, and during the entire period of the study, subjects have continued to regularly take oral alpha lipoic acid at a dose of $600 \mathrm{mg}$ (one tablet a day, in the morning before breakfast).

On patient admission and upon the completion of the last (third) diagnostic and therapeutic cycle (after 6 months) an analysis of EMNG of the sensory and motor nerves of the lower extremities was conducted (n. peroneus and n. suralis). EMNG testing was performed using the latest-generation Medtronic Keypoint (Denmark, Skovlunde, www.medtronic.com). The duration of the procedure was about 45 minutes, including reading of the results. The method examines individual nerve conduction velocity by registering evoked potentials directly from the sensitive fibers, while the motor fibers are tested through evoked potentials with or from muscles innervated by these neurons. The procedure does not require any preparation, and it is performed by placing surface (skin) and/or deep electrodes, usually both types of electrodes, as decided by the doctor who is performing the examination of $n$. peroneus and $n$. suralis.

The median value, standard deviation (SD), median, minimum and maximum values, as well as the normality of the distribution of all continuous variables were determined, using the Shapiro-Wilk test. In order to compare the mean values of continuous variables within the tested groups, the paired $t$-test was used for data sets with normal distribution, or alternatively Wilcoxon's test of matched pairs. Differences between the compared groups were investigated using the independent t-test or the Mann-Whitney test data sets without a normal distribution. The $\chi^{2}$ test was used to compare the frequency (incidence) of categorical (dichotomous) variables. Statistical significance was accepted for all the results where the probability of the null hypothesis was less than $5 \%(\mathrm{p}<0.05)$. The research results are presented in tabular form. All statistical calculations were carried out using the commercial software package SPSS version 20.0.

\section{RESULTS}

The basic characteristics of the patients in group A, the physical therapy group and group B, the alpha lipoic acid group are given in Table 1. Both groups were homogeneous by gender $(\mathrm{p}=0.598)$, diabetes mellitus genetic heritage $(\mathrm{p} \approx 1.000)$, active cigarette smoking $(p=0.347)$, profession $(p=0.837)$, age $(p=0.09)$, body mass index $(p=0.773)$, duration of $D M(p=0.09)$ and laboratory test results: HbA1c $(\mathrm{p}=0.403)$, urea $(\mathrm{p}=0.679)$, and creatinine $(\mathrm{p}=0.524)$.

Table 2 shows the results of the electroneurographic test of $n$. peroneus. At the end of the intervention there were statistically significant improvements in terminal latency $(\mathrm{p}<0.001)$ and the amplitude of the action potency $(\mathrm{p}=0.032)$ in group A patients, while in group B patients showed statistically significant improvements in conduction velocity $(\mathrm{p}<0.001)$ and terminal latency $(\mathrm{p}=0.001)$ of $\mathrm{n}$. peroneus. At the beginning of the study group A and group B showed no significant differences in the monitored electroneurographic parameters; they were homogeneous in speed of enforcement, $p=0.385$, terminal latency

Table 1. Characteristics of the patients with DSMP

\begin{tabular}{|c|c|c|c|c|}
\hline \multicolumn{2}{|l|}{ Characteristic } & Group A $(n=30)$ & Group B $(n=30)$ & Significance \\
\hline \multicolumn{5}{|l|}{ number $(\%)$} \\
\hline Gender & $\begin{array}{l}\text { male } \\
\text { female }\end{array}$ & $\begin{array}{l}11(36.7 \%) \\
19(63.3 \%)\end{array}$ & $\begin{array}{l}13(43.3 \%) \\
17(56.7 \%)\end{array}$ & no \\
\hline Hereditary DM & $\begin{array}{l}\text { Yes } \\
\text { No }\end{array}$ & $\begin{array}{l}13(43.3 \%) \\
17(56.7 \%)\end{array}$ & $\begin{array}{l}13(43.3 \%) \\
17(56.7 \%)\end{array}$ & no \\
\hline Active smoking & $\begin{array}{l}\text { Yes } \\
\text { No }\end{array}$ & $\begin{array}{c}8(26.7 \%) \\
22(73.3 \%)\end{array}$ & $\begin{array}{c}5(16.7 \%) \\
25(83.3 \%)\end{array}$ & no \\
\hline \multicolumn{4}{|l|}{ mean $\pm \mathrm{SD}$} & no \\
\hline \multicolumn{2}{|l|}{ Age (years) } & $63.2 \pm 7.7$ & $62.8 \pm 8.3$ & no \\
\hline \multicolumn{2}{|c|}{ Body Mass Index $\left(\mathrm{kg} / \mathrm{m}^{2}\right)$} & $27.2 \pm 4.6$ & $27.2 \pm 3.9$ & no \\
\hline \multicolumn{2}{|c|}{ Duration of diabetes (yr) } & $12.2 \pm 7.6$ & $11.7 \pm 5.7$ & no \\
\hline \multicolumn{2}{|l|}{ HbAlc (\%) } & $7.8 \pm 1.9$ & $7.3 \pm 1.2$ & no \\
\hline \multicolumn{2}{|l|}{ Urea $(\mathrm{mmol} / \mathrm{l})$} & $6.5 \pm 2.9$ & $6 \pm 2.1$ & no \\
\hline \multicolumn{2}{|c|}{ Creatinine $(\mu \mathrm{mol} / \mathrm{l})$} & $81.1 \pm 22.2$ & $76.3 \pm 17.7$ & no \\
\hline \multicolumn{2}{|c|}{ Motor conduction velocity of $n$. peroneus } & $40.6 \pm 3.8$ & $39.5 \pm 5.1$ & no \\
\hline \multicolumn{2}{|c|}{ Sensory conduction velocity of $n$. suralis } & $31.8 \pm 21$ & $31.6 \pm 24.1$ & no \\
\hline
\end{tabular}

p: retired; e: employed; ue: unemployed 
$\mathrm{p}=0.849$ and amplitude of action potential $\mathrm{p}=0.525$. At the end of the intervention there were again no significant differences in the speed of implementation $(\mathrm{p}=0.845)$, terminal latency $(\mathrm{p}=0.563)$, or the amplitude of the action potency $(\mathrm{p}=0.881)$.

Table 3 shows the results of the electroneurographic examination of $n$. suralis. At the end of the intervention in group A patients showed statistically significant improvements in conduction velocity $(p<0.001)$ and terminal latency $(p=0.014)$, while group B patients also showed statistically significant improvement in conduction velocity $(\mathrm{p}=0.007)$ and terminal latency $(\mathrm{p}=0.008)$, too. At the beginning of the study group A and group B showed no significant differences in the monitored ENG parameters; they were homogeneous in enforcement speed, $p=0.658$, terminal latency $p=0.576$ and amplitude of action potential $\mathrm{p}=0.489$. At the end of the intervention, there were again no significant differences in speed of implementation $(\mathrm{p}=0.794)$, terminal latency $(\mathrm{p}=0.737)$, or the amplitude of the action potency $(\mathrm{p}=0.372)$.

\section{DISCUSSION}

The results of our study show that both treatment modalities, alpha-lipoic acid and the program of physical therapy, improved the electromyoneurography parameters of the patients with diabetic neuropathy, with approximately comparable extent. A larger number of studies have examined the effects of the physical therapy and alpha lipoic acid in patients with neuropathy. However, the variety of physical methods, treatment protocols, patient characteristics and etiological factors of neuropathy results in a distinct methodological heterogeneity, which is why the results can only be indirectly compared to each other, and to the results of our study, as well.

A clinical study ${ }^{15}$ ) showed the effect of pulsed electromagnetic fields on the regeneration of nerves in patients with DSMP, but without a statistically significant reduction of pain (VAS). In the study by Bosy et al. ${ }^{16}$ ), an increase in the speed of conduction was found through $\mathrm{n}$. peroneus after application of magnetic therapy to n. suralis. Our results are consistent with that study, except that in our study, in addition to a magnetic therapy, electrotherapy (TENS and SG) was applied, too.

In the study by Graack et al. ${ }^{17)}$, after application of electromagnetotherapy, a statistically significant reduction the distal latency of $n$. peroneus and a significant increase in the speed of conduction through n.peroneus were shown, but there was no significant change in the amplitude of the action potential of $n$. peroneus. Our results also indicated there was a statistically significant increase in the speed of conduction through n.peroneus in group B patients, and a reduction in the distal latency of n.peroneus in both groups of A and B; however, no statistically significant difference was found between the two therapeutic

Table 2 . Nerve conduction study results for n.peroneus

\begin{tabular}{llccc}
\hline Parameter & & Group A $(\mathrm{n}=30)$ & Group B $(\mathrm{n}=30)$ & Significance \\
\hline $\begin{array}{l}\text { Motor conduction velocity of n.peroneus } \\
(\mathrm{m} / \mathrm{s})\end{array}$ & before & $40.6 \pm 3.8$ & $39.5 \pm 5.1$ & no \\
& after & $41.6 \pm 4.4$ & $41.1 \pm 5$ & no \\
& Significance & no & $* * *$ & \\
Distal latency of n.peroneus & before & $4 \pm 1$ & $4.2 \pm 1.5$ & no \\
$(\mathrm{ms})$ & after & $3.5 \pm 1$ & $3.8 \pm 1.4$ & no \\
& Significance & $* * *$ & $* * *$ & no \\
Action potential amplitude of n.peroneus & before & $3.8 \pm 2.2$ & $3.3 \pm 2.2$ & no \\
$(\mathrm{mV})$ & after & $4.4 \pm 2.6$ & $3.6 \pm 2.1$ & no \\
& Significance & $*$ & & \\
\hline
\end{tabular}

Group A: physical therapy; Group B: alpha lipoic acid; * $<0.05 * *<0.01 * * *<0.001$

Table 3 . Nerve conduction study results for n.suralis

\begin{tabular}{llccc}
\hline Parameter & & Group A $(\mathrm{n}=30)$ & Group B (n=30) & Significance \\
\hline $\begin{array}{l}\text { Sensory conduction velocity of n.suralis } \\
(\mathrm{m} / \mathrm{s})\end{array}$ & before & $31.8 \pm 21$ & $31.6 \pm 24$ & no \\
& after & $40.1 \pm 25.6$ & $32.2 \pm 27.7$ & no \\
& Significance & $* * *$ & $* *$ & \\
Distal latency of n.suralis & before & $2.6 \pm 2.8$ & $2.1 \pm 1.7$ & no \\
$(\mathrm{ms})$ & after & $1.9 \pm 1.4$ & $1.8 \pm 1.5$ & no \\
& Significance & $*$ & $2.7 \pm 2.7$ & no \\
Action potential amplitude of n.suralis & before & $2.9 \pm 2.3$ & $2.7 \pm 2.8$ & no \\
$(\mathrm{mV})$ & after & $3 \pm 2.7$ & no & \\
\hline
\end{tabular}

Group A: physical therapy; Group B: alpha lipoic acid; $*<0.05 * *<0.01 * * *<0.001$ 
modalities. Unlike the study by Graack et al., the therapy applied in our study increased the amplitude of the action potential of n. peroneus in group A patients.

A four-year study ${ }^{18)}$ reported that the performance of exercise resulted in a statistically significant increase in the speed of conduction through n. peroneus, while the conduction velocity through n. suralis did not significantly change. Several other studies have confirmed these results ${ }^{19-22)}$. In our present study, the performance of exercise combined with magnetotherapy and electrotherapy also achieved a significant increase in the speed of conduction through n.peroneus in group B patients, but the application of these physical agents also significantly increased the speed of conduction through $\mathrm{n}$. suralis.

A study by Fisher et al. ${ }^{23}$ ) demonstrated statistically significant improvements in EMNG parameters (speed of conduction, amplitude and latency through the motor and sensory nerves) after a 24-week exercise program for patients with DSMP. Our results are in agreement with the results of that study, but out method differed in that it combined training with electrotherapy and magnetotherapy. There was also a difference in the duration of treatment: physical therapy was shorter in our study than in the study by Fischer et al.

A study ${ }^{24)}$ showed that the use of alpha lipoic acid in the treatment of DSMP led to a significant increase in the speed of conduction through n. peroneus and $\mathrm{n}$. suralis which partially matches the results of our present study. These results suggest beneficial effect of combining these two methods of treatment for patients with DSMP, which should be studied in future research.

The application of physical agents and alpha lipoic acid mentioned above favorably influenced the course and outcome of patients with symmetrical distal sensorimotor diabetic polyneuropathy. This was reflected in a significant improvement in electrophysiological parameters (conduction velocity, amplitude and latency) of the motor and sensory nerves (n. peroneus, $n$. suralis). These results present further evidence in favour of the use of physical agents in the treatment of diabetic sensorimotor polyneuropathy. They also contribute to the theoretical basis for the planning of further investigations of other important aspects of different therapeutic strategies, such as the efficacy and safety of combined treatments and economic studies.

\section{ACKNOWLEDGEMENT}

This study was supported by Serbian Ministry of Science (Grant ON175061).

\section{REFERENCES}

1) Daousi C, MacFarlane IA, Woodward A, et al.: Chronic painful peripheral neuropathy in an urban community: a controlled comparison of people with and without diabetes. Diabet Med, 2004, 21: 976-982. [Medline] [CrossRef]

2) Abbott CA, Malik RA, van Ross ER, et al.: Prevalence and characteristics of painful diabetic neuropathy in a large community-based diabetic population in the U.K. Diabetes Care, 2011, 34: 2220-2224. [Medline] [CrossRef]

3) Tesfaye S, Boulton AJ, Dyck PJ, et al. Toronto Diabetic Neuropathy Expert Group: Diabetic neuropathies: update on definitions, diagnostic criteria, estimation of severity, and treatments. Diabetes Care, 2010, 33: 2285-2293. [Medline] [CrossRef]

4) Kang JH, Lee YS: Sensory nerve conduction studies in the diagnosis of diabetic sensorimotor polyneuropathy: electrophysiological features. J Phys Ther Sci, 2012, 24: 139-142. [CrossRef]

5) England JD, Gronseth GS, Franklin G, et al. American Academy of Neurology, American Association of Electrodiagnostic Medicine, American Academy of Physical Medicine and Rehabilitation: Distal symmetric polyneuropathy: a definition for clinical research: report of the American Academy of Neurology, the American Association of Electrodiagnostic Medicine, and the American Academy of Physical Medicine and Rehabilitation. Neurology, 2005, 64: 199-207. [Medline] [CrossRef]

6) Boulton AJ: Diabetic neuropathy: classification, measurement and treatment. Curr Opin Endocrinol Diabetes Obes, 2007, 14: 141-145. [Medline] [CrossRef]

7) Ziegler D: Treatment of diabetic neuropathy and neuropathic pain: how far have we come? Diabetes Care, 2008, 31: S255-S261. [Medline]

8) Poh ZX, Goh KP: A current update on the use of alpha lipoic acid in the management of type 2 diabetes mellitus. Endocr Metab Immune Disord Drug Targets, 2009, 9: 392-398. [Medline] [CrossRef]

9) Ziegler D, Nowak H, Kempler P, et al.: Treatment of symptomatic diabetic polyneuropathy with the antioxidant alphalipoic acid: a meta-analysis. Diabet Med, 2004, 21: 114-121. [Medline] [CrossRef]

10) Melzack R, Wall PD: Pain mechanisms: a new theory. Science, 1965, 150: 971-979. [Medline] [CrossRef]

11) Park RJ, Son H, Kim K, et al.: The effect of microcurrent electrical stimulation on the foot blood circulation and pain 
of diabetic neuropathy. J Phys Ther Sci, 2011, 23: 515-518. [CrossRef]

12) Ziegler D, Low PA, Boulton AJ, et al.: Effect of 4-year antioxidant treatment with alpha-lipoic acid in diabetic polyneuropathy: The NATHAN Trial [abstract]. Diabetes, 2007, 56: A2.

13) Maggi G, Monti Bragadin M, Padua L, et al.: Outcome measures and rehabilitation treatment in patients affected by Charcot-Marie-Tooth neuropathy: a pilot study. Am J Phys Med Rehabil, 2011, 90: 628-637. [Medline] [CrossRef]

14) Dennis D, Mullins R: Guillain-Barré syndrome patient's satisfaction with physiotherapy: a two-part observational study. Physiother Theory Pract, 2013, 29: 301-308. [Medline] [CrossRef]

15) Weintraub MI, Herrmann DN, Smith AG, et al.: Pulsed electromagnetic fields to reduce diabetic neuropathic pain and stimulate neuronal repair: a randomized controlled trial. Arch Phys Med Rehabil, 2009, 90: 1102-1109. [Medline] [CrossRef]

16) Bosi E, Conti M, Vermigli C, et al.: Effectiveness of frequency-modulated electromagnetic neural stimulation in the treatment of painful diabetic neuropathy. Diabetologia, 2005, 48: 817-823. [Medline] [CrossRef]

17) Graak V, Chaudhary S, Bal BS, et al.: Evaluation of the efficacy of pulsed electromagnetic field in the management of patients with diabetic polyneuropathy. Int J Diabetes Dev Ctries, 2009, 29: 56-61. [Medline] [CrossRef]

18) Balducci S, Iacobellis G, Parisi L, et al.: Exercise training can modify the natural history of diabetic peripheral neuropathy. J Diabetes Complications, 2006, 20: 216-223. [Medline] [CrossRef]

19) Tamura T, Kida K, Seki T, et al.: Study of the relationship between exercise therapy and diet therapy in type 2 diabetes mellitus patients. J Phys Ther Sci, 2011, 23: 485-488. [CrossRef]

20) Lucha-López MO, Lucha-López AC, Vidal-Peracho C, et al.: Impact of supervised physiotherapeutic exercises for obese adults with diabetes mellitus type 2. J Phys Ther Sci, 2012, 24: 1299-1305. [CrossRef]

21) Endo $Y$, Oyunchimeg C, Nakagawa K, et al.: Evaluation of an exercise program for diabetic patients in mongolia. J Phys Ther Sci, 2013, 25: 245-248.

22) Noh JW, Park JE, Jung JH, et al.: Exercise is associated with metabolism regulation and complications in Korean patients with type 2 diabetes. J Phys Ther Sci, 2015, 27: 2189-2193. [Medline] [CrossRef]

23) Fisher MA, Langbein WE, Collins EG, et al.: Physiological improvement with moderate exercise in type II diabetic neuropathy. Electromyogr Clin Neurophysiol, 2007, 47: 23-28. [Medline]

24) Han T, Bai J, Liu W, et al.: A systematic review and meta-analysis of $\alpha$-lipoic acid in the treatment of diabetic peripheral neuropathy. Eur J Endocrinol, 2012, 167: 465-471. [Medline] [CrossRef] 